\title{
ON DIFFERENTIAL DIAGNOSIS BETWEEN AUTISTIC DISORDER AND ASPERGER'S SYNDROME
}

\author{
Stefan Todorov, Mariana Arnaoudova \\ Department of psychiatry, Medical University - Varna; Third psychiatric Clinic, \\ University Hospital "St. Marina" - Varna, Bulgaria
}

\section{SUMMARY}

The differential diagnosis between Autistic disorder (AD) and Asperger's syndrome (AS) in most cases is quite difficult since most of the symptoms are clinically undistinguished. Several factors complicate the diagnosis of AS- an autism spectrum disorder (ASD). It is considered by some authors to be simply a milder version of autistic disorder. Problems in diagnosis include disagreement among diagnostic criteria, controversy over the distinction between AS and other ASD forms or even whether AS exists as a separate syndrome, and over- and under-diagnosis.

Our paper is based on the diagnostic and differential diagnostic criteria of DSM-IV, ICD-10 and our clinical experience.

In the process of diagnosis and differential diagnosis we, naturally, illustrate and discuss the similarities and differences between the two disorders.

Key words: autistic disorder, Asperger's syndrome, differential diagnosis

\section{INTRODUCTION}

The differential diagnosis between Autistic disorder (AD) and Asperger's syndrome (AS) in most cases is quite difficult since most of the symptoms are clinically undistinguished. Several factors complicate the diagnosis of AS- an autism spectrum disorder (ASD). It is considered by some authors to be simply a milder version of autistic disorder, suggesting that there is too little evidence clearly to single out the entity of Asperger's syndrome from the spectrum of autistic syndromes $(1,2,3,4)$. Others support the distinguishing AS from $\mathrm{AD}$, nevertheless the commonalities between the two disorders $(5,6)$.

Problems in diagnosis include disagreement among diagnostic criteria, controversy over the distinction between AS and other ASD forms or even whether AS exists as a separate syndrome, and overand under-diagnosis.

According to ICD-10 (1993) and DSM-IV-TR (2000) AD and AS are currently defined under the category of pervasive developmental disorders $(7,8)$.

\section{SUBJECTS AND METHODS}

The aim of our work, based on literature data and on our clinical experience ( 28 children with autism16 boys and 5 girls and 7 with AS- 5 boys and 2 girls), is to discuss some essential diagnostic and differential diagnostic criteria of these two disorders, which would be of practical everyday use for medical, social, educational and other services, dealing with such patients.

\section{RESULTS AND DISCUSSION}

From a historical point of view autism has been described for a first time by L. Kanner (1943). He formulated criteria, which have been added, modified and specified in different classifications later on (9). We should point out that in the first and in the second version of APA classifications (DSM-I, 1953 and DSM-II, 1968) the term autism was not elicited, and children, suffering from this disorder have been classified as children schizophrenia. In the third version of APA (DSM-III, 1980) autism was included in the category of pervasive developmental disorders as a distinct disorder $(10,11,12)$. In DSM-IV (1994) and in DSM-IV-TR (2000) autism is defined as a psychopathological disorder, which is characterized as an impairment of many functions in the whole development of the child, manifested in the first 3 years of his life. It is more common in males than in females with a ratio of $4: 1$. In IDC-10 (1993) three main domains of abnormal type of functioning are described: 
of social relations; communications and behavior repertoire, which is confined and stereotyped.

The basic diagnostic criteria in contemporary classifications:

1. onset of the symptoms prior to age 3 years:

2. delays or abnormal functioning of social interactions;

3. qualitative impairment in verbal and nonverbal communications, including lack of emotional reciprocity;

4. delays or difficulties in development of cognitive functioning, a relative lack of creativity and fantasy of thinking processes;

5. rigid, repetitive, stereotyped patterns of behavior, interests and activities, manifested by the requirement of an unalterable order in a large range of everyday functioning.

Asperger's syndrome is named after the Austrian pediatrician Hans Asperger, 1944. He studied and described 4 children in his practice, who lacked nonverbal communication skills and had difficulties in social adaptation. He related this disorder to psychopathy with social isolation under the name "autistic psychopathy" $(13,14)$.

For a long time his work remained unknown. The modern conception of AS came into existence in 1981, when L. Wing published series of examined patients with familiar symptoms and named the disorder "Asperger's syndrome". (1)Boys are five times more likely than girls to be affected by AS. (The syndrome is much more common in boys than in girls-5:1). It became standardized as a diagnosis in the early 1990's in ICD-10 (1994), DSM-IV (1994) and is currently defined under the category of pervasive developmental disorder, being an important matter research and discussion $(15,16)$

Asperger's syndrome is distinguished by a pattern of symptoms, rather than a single symptom. It is characterized by qualitative impairment in social interaction, by stereotyped and restricted patterns of behavior, activities and interests. The differences from $\mathrm{AD}$ are the lack of clinically significant delay in cognitive development or general delay in language and onset after 3 years of age.

In all of the seven AS patients, diagnosed and observed by us, the disorder appeared after 3 years of age and no delay in cognition and language was registered. The lack of demonstrated empathy was possibly the most dysfunctional aspect of AS patients. Individuals with AS, like autistic ones experience difficulties in basic elements of social interaction, because they are insufficient to recognize the signals, reactions and feelings of others. Other important feature is the delay in motor development. They begin to walk later, have difficulties in performance of everyday activities (dressing, washing, grooming, using cutlery), have difficulties in education, although their relative normality of intelligence and language. Like autistic children they dislike any changes in routines. People with AS often display behavior, interests, and activities that are restricted and repetitive and are sometimes abnormally intense or focused. Any changes make them nervous, even aggressive. They have heightened sensitivity and become over stimulated or even aggressive by loud noises, lights, crowds or strong tastes or textures.

As we mentioned before, children with AS do not have a delay in their intellectual development and speech. Nevertheless, language acquisition and use is often atypical.

Individuals with AS may collect volumes of detailed information on a relatively narrow topic, that is of interest only for themselves. Pursuit of specific and narrow areas of interest is one of the most striking features of AS Sometimes they provoke real surprise with their knowledge and the ability to commit to memory knowledge in mathematics, music, arts, geography, spatial orientation. Their expertise, an unusual sophisticated vocabulary of vocabulary, and formal speech patterns make them seem like "little professors." In this context, we would like to underline that not all autistic children have an intellectual retardation. Information is for about $70-75 \%$ of them (17). Others, that don't have such a problem, are considered as high level AD. Intellectual and language retardation was registered in 17 of diagnosed and observed AD children.

People with AS may not be as withdrawn around others as autistic ones; they approach others, even if awkwardly. They are looking for attention, able to speak for hours on questions and problems of importance only for them.

\section{CONCLUSION}

A crucial distinctive point between $\mathrm{AD}$ and AS appears to be the level of cognitive function and the time of onset. Autistic disorder begins before 3 years of age and cognitive functions are impaired, while AS is most commonly diagnosed between ages four and 
eleven without significant delay in language or cognitive development. Other distinctive characteristics are much more subjective and practically impossible to be distinguished. The same problem exists with highfunctioning autistic patients, where, due to different reasons, the onset of the disorder is vague. The correct diagnosis is of great importance for the choice of adequate therapeutic approach. Further research of theoretical and mainly of clinical aspects would enrich and precise some diagnostic and differential-diagnostic criteria between the two disorders.

\section{REFERENCES:}

1. Wing L. Asperger's syndrome: a clinical account. Psychol Med. 1981 Feb;11(1):115-29. [PubMed]

2. Gillberg C. Asperger's syndrome and recurrent psychosis- A case study. J Autism Dev Disord. 1985; 15(4):389397. [CrossRef]

3. Levy S. Identifying highfunctioning children with autism. Bloomington 1988 IN: Indiana Resource Center for Autism.

4. Wing L. The relationship between Asperger's syndrome and Kanner's autism. in Frith U. Autism and Asperger syndrome. Cambridge University Press 1991: 93-121. ISBN 0-521-38608-X.

5. Wolf S, Barlow A. Schizoid personality in childhood. $J$ Child Psychol Psychiatry 1979; 20: 29-46.

6. Tantam D. Asperger syndrome. $J$ Child Psychol Psychiatry 1988 May;29(3):245-255. [CrossRef]

7. WHO. The ICD-10 classification of mental and behavioral disorders: diagnostic criteria for research. Geneva: World Health Organization; 1993.

8. American Psychiatric Association: Diagnostic and statistical manual of mental disorders (DSM-IV), 2000, (4 ${ }^{\text {th }}$ ed., text rev.) Washington, DC: APA. [CrossRef]

9. Kanner L. Autistic disturbances of affective contact. Nervous Child, 1943; 2:217-250.

10. American Psychiatric Association: Diagnostic and statistical manual of mental disorders (DSM-I), 1955, Washington, DC: APA.

11. American Psychiatric Association: Diagnostic and statistical manual of mental disorders (DSM-II) 1968, Washington, DC: APA.

12. American Psychiatric Association: Diagnostic and statistical manual of mental disorders (DSM-III),
1980, Washington, DC: APA.

13. Asperger H. Problems of infantile autism. Communication, 1979; 12:45-52.

14. Asperger H. (1991). "Autistic psychopathy" in childhood. In Frith U (Ed. and Trans.) Autism and Asperger syndrome (37-92) Cambridge University Press. (Original work published 1944) ISBN 0-521-38608-X.

15. McPartland J, Klin A. Asperger's syndrome. Adolesc Med Clin. 2006 Oct;17(3):771-88. [PubMed] [CrossRef]

16. Baskin JH, Sperber M, Price BH. Asperger syndrome revisited. Rev Neurol Dis. 2006 Winter;3(1):1-7. [PubMed]

17. Schopler E. Are autism and Asperger syndrome different labels or different disabilities? J Autism Dev Disord. 1996 Feb;26(1):109-110. [PubMed] [CrossRef]

Address for correspondence:

Assoc. prof. Mariana Arnaoudova, MD, PhD

MHAT 'St. Marina”,

1, Hr. Smirnenski str., Varna 9010, Bulgaria

phone: 00359888512627

e-mail:marnaudova@hotmail.com; 